\title{
The Design and Development of Virtual Elevator Assistant Training System
}

\author{
Zhangwei Ling ${ }^{1,}$, Junfang Xia ${ }^{1, b}$, Min Wang ${ }^{1, c}$ and Ping Tang ${ }^{1, d}$ \\ ${ }^{1}$ Zhejiang Provincial Special Equipment Inspection and Research Institute, Hangzhou 310020, \\ China. \\ alingzhangwei@163.com, bxiajunfang123@163.com, 'wangmin@nbu.edu.cn, \\ tangpingjob@163.com
}

Keywords: Elevator, virtual simulation, assistant training.

\begin{abstract}
Aiming at the problem of assistant teaching and training system for the elevator operator and maintenance operators, the present professional training patterns were analyzed. The virtual elevator system was applied to the elevator training areas, based on the 'Examination requirements for Safety Administrator and Operators of Elevator'. The assistant training system for virtual elevator was designed and developed, using the computer technology, multimedia technology and virtual instrument technology. The system can realize the training for student on the principle, administration of elevator from ancillary staff and improve the teaching efficiency and training level.
\end{abstract}

\section{Introduction}

The number of elevator growth rapidly in recent years, while the maintenance technology is irregularity and the installation and maintenance market has not been normalized, the phenomenon of low-cost-low-quality is serious. Since the misuse of elevator, not in place of maintenance and many others factors, the specialization requirements of the relevant technical staff become increasingly higher. Therefore high quality elevator training emerges in response to the needs of times. However, the development of elevator model unable to keep pace with the vocational skills training, it is time to improve the present elevator training system, for meeting the needs of the elevator technicians. Now, the elevator training institutions are actively exploring the more scientific and effective development approach, carrying on the training reform, setting up excellent courses and paying great attention to the innovation of integration training system.

The virtual elevator system, with the analog simulation features the training pattern, replaces the traditional way of "the master train an apprentice", which all the student study in a unified quantitative framework. The simulation training environment, abandoned the inflexible teaching pattern of written material and documents and established by information technology, has the teaching situation of self-participations, makes seamlessly combination between the study and work. The new training system optimizes the traditional training system, which affected by teachers, cost, training equipment, operating accidents, and saves a lot of training material and expensive training equipment.

Therefore, the virtual elevator system applied to the elevator training areas has a certain economic, social benefits and wide promotion space. The system can highlight the quantitative organization method of training courses and match up rich learning resources, specific simulation operation, and can realizes the assistant training for the student on the operating principle, analog installation and safety management of elevator from ancillary staff by flexible using computer technology, multimedia technology and virtual instrument technology. The system can makes training outcomes controllable and measurable, which greatly solves the bottleneck problem of elevator industry in the current training mode and improves the professional quality of the elevator technicians. 


\section{System Structure}

Summary. The elevator is a vertical transportation vehicle, closely linking with people's daily life, which consist of tractor, control cabinet, door, guide rail, over-speed governor, buffer, counterweight, etc. The elevator actually is a man-machine interactive control system, running on random external call and personal control law. The overall structure of the elevator can be divided into the electrical control system, electric drive system, door system, car system, traction system, guidance system, safety protection system and weight balanced system. According to the position, the elevator can be divided to four parts: elevator machine room, lift well, elevator car, elevator floor. In mechanical systems, the elevator manufacturers mainly design elevator car and balance weight part. The other parts, such as tractor, buffer, portal crane, are selective assembly on the basis of velocity, deadweight, power of elevator.

The system mainly used for education, in which the elevator structure can be designed according to the instructional needs. And the system can simulates the elevator running and control function, including the logic function of elevator running, hall call, car call and other real call signal, select signal, control signal. The simulation program interface of virtual elevator mainly realizes the man-machine interactive function and shows the result feedback, including elevator running status signals, elevator configuration, control signal, door status, car signal, etc. Making the elevator model easy to understand, the elevator model omits the part structure which not related to the elevator control logic relations in the simulation of elevator running logic. Thus, the elevator model can realizes the switching design of key structure floor in the elevator logic control, and can express the running state model using animation. The system mainly designs the external request button, capsules request button, leveling switch and other main functions, omitting the tractor, counterweight, safety device.

System Analysis. The system modularized designs elevator training process in the form of software, combined with object-oriented design. The elevator physical composition, critical component, operating principle, installation process, test standard, basic theory, operation procedure, simulation practice of system are mainly studied. In addition, the system also constructs relevant information training knowledge base and standard base based on database technology, to supporting extended activity and simulating examine for student. The system has learning feedback analysis functions, which can statistically analysis the module grades of all students and visually shows in the form of chart.

The participants in the system are the users and operators of the system. Thus, it is meaning to analysis the participants. The user use case diagram as shown in the Fig. 1.

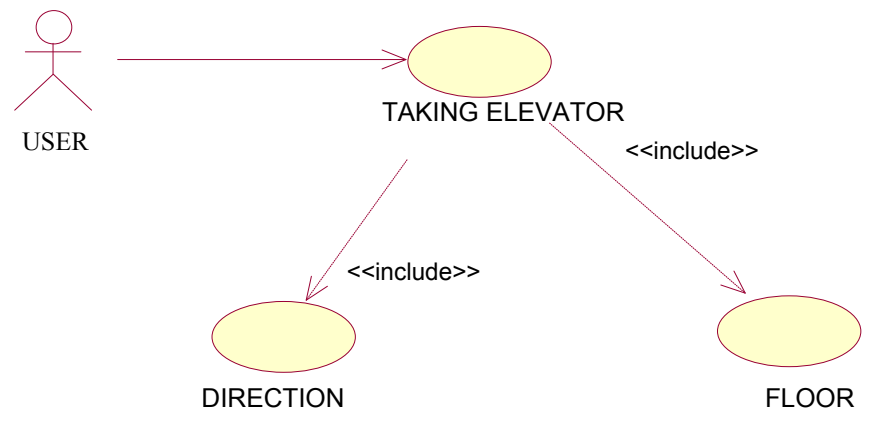

Fig. 1 User use case diagram

The design floor of elevator has 11 floors. The middle floor has two buttons, up and down. The bottom floor only has the up button, and the top floor only has the down button. By class diagram and collaboration diagram of system, the system can be analyzed from different angles, which will be beneficial to deepen the understanding to the system. Then, it will lay the foundation for successfully developing system, as shown in Fig. 2 and Fig. 3. 


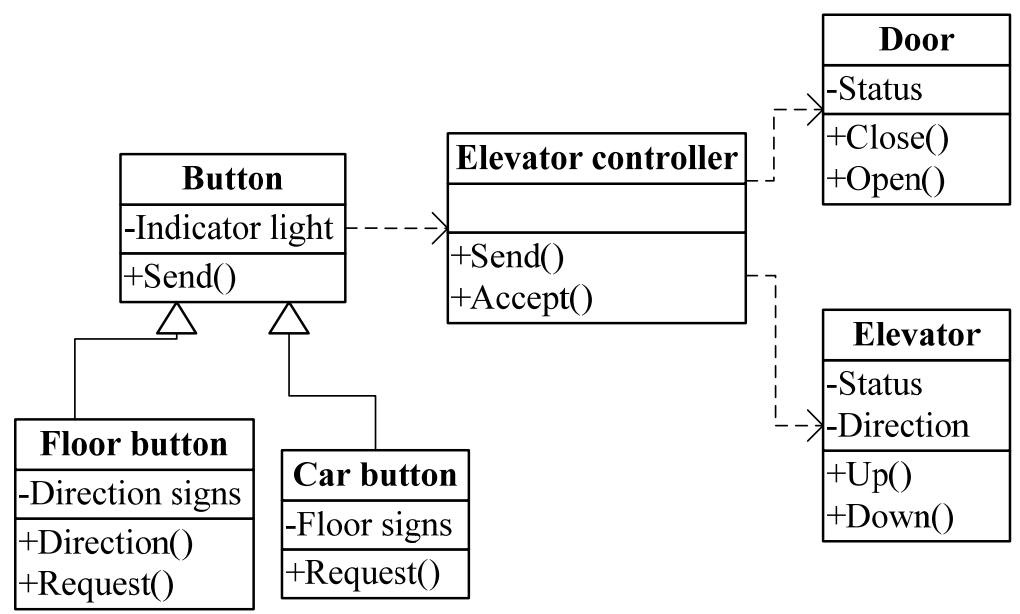

Fig. 2 Class diagram of system

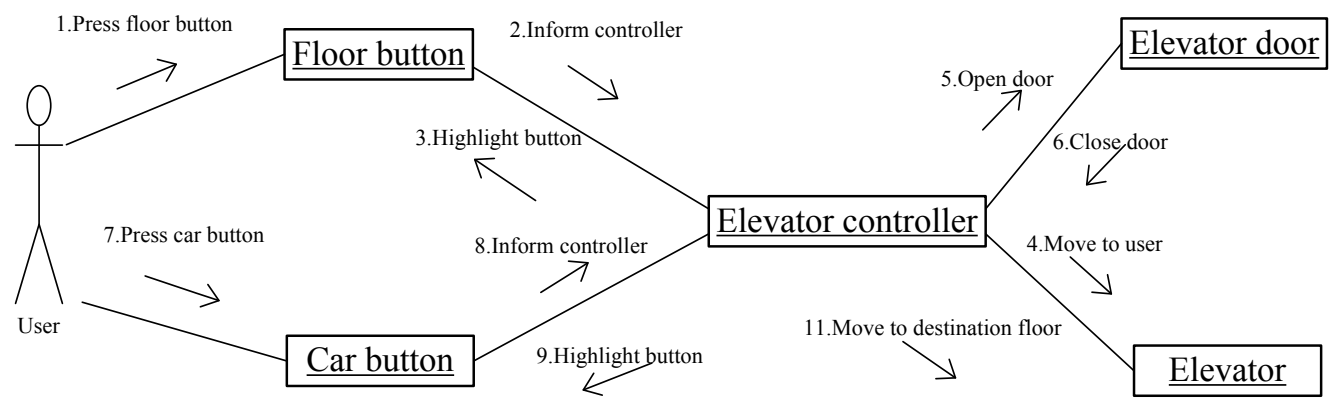

Fig. 3 Collaboration diagram of system

\section{Design and Development}

System Design. The vertical running elevator consists of tractor, roadway, counterweight, safety device, signal control system, elevator car, etc. The system mainly simulates elevator control, including elevator call, layer selection, deceleration, pit stop, etc. For simplifying interface and outstanding the main functions, the system mainly designs the external request button, capsules request button and other major functions during the model design, omitting the tractor, counterweight, installation device. The system program contains six program modules.

(1) Main program module

(2) Passenger module

(3) Passenger stack module

(4) Elevator module

(5) Waiting queue module

(6) Floor module

The scheduling relationship between each module as shown in Fig. 4: 


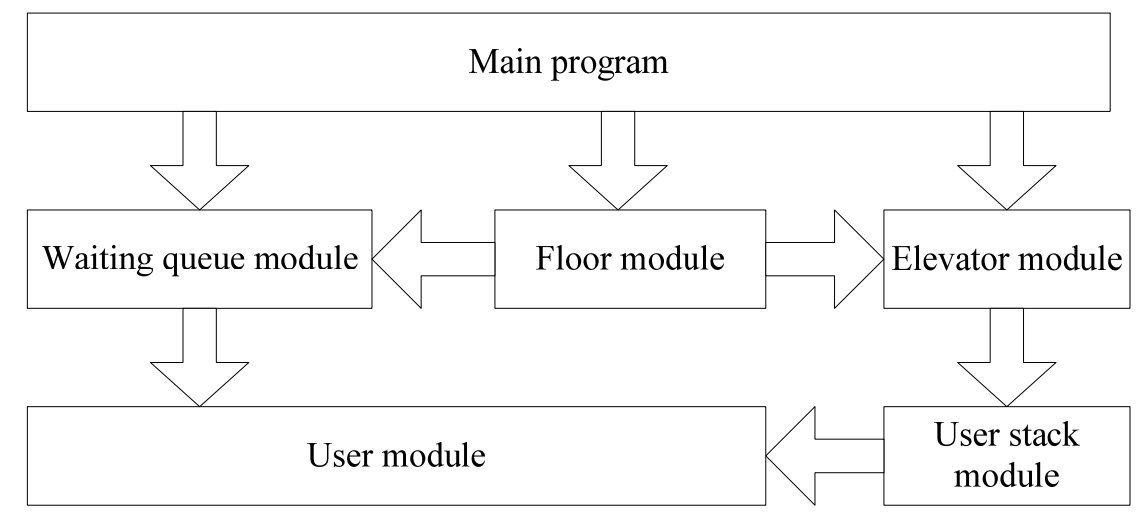

Fig. 4 The scheduling relationship

The elevator operating criteria contains automatic response to each floor call signal (include up and down call), automatic response to service command signal in capsules which first be responded, control loop on service principle. And all the call signals are automatic oriented by the principle of first come, first served.

Function Realization. The virtual elevator system simulates elevator running and control function by adopting the $\mathrm{VC}++$ program design, including the logic function of elevator running, hall call, car call and other real call signal, select signal, control signal.

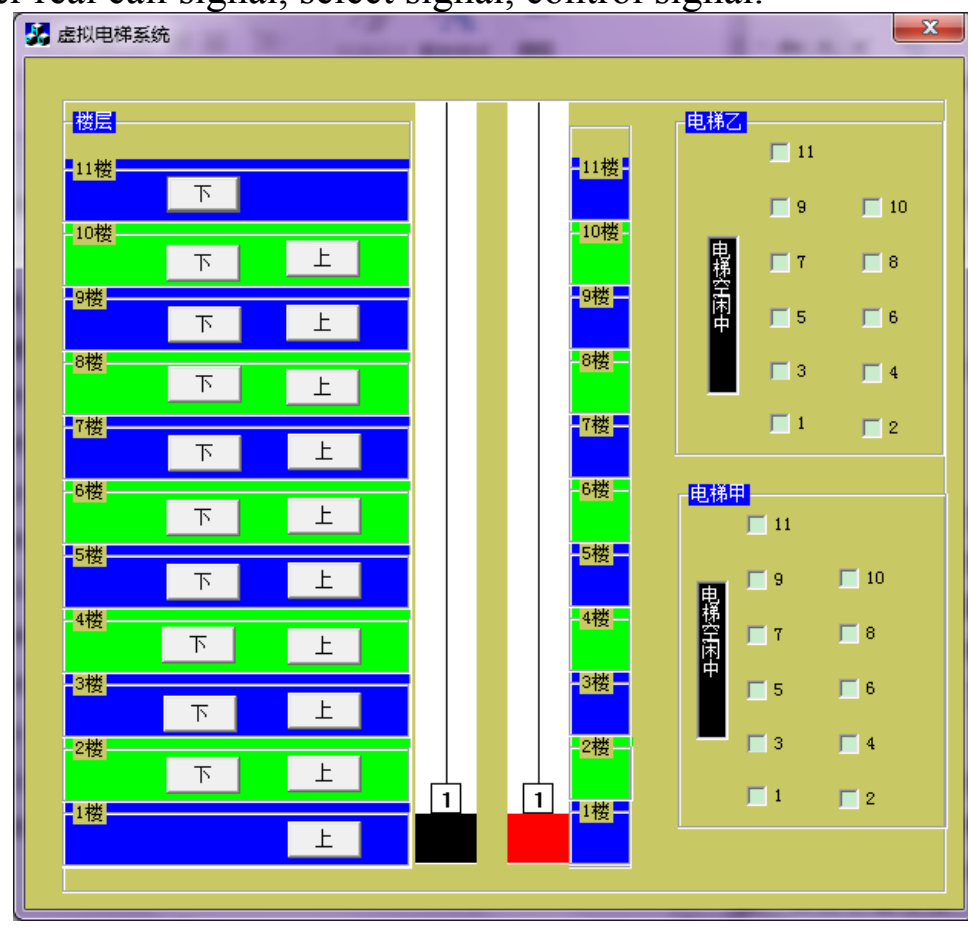

Fig. 5 The virtual elevator system

An elevator normally is standby at base station, which called base elevator. The other one stay at the last stopping floor, called busing elevator. Since the car order, both elevators close the door to standby after get to the base. And when there is the outside call signal, the one who first come to the base station to process instruction.

When the busing elevator lifts up, the any direction calls from above the elevator and the downward call from below the elevator will be finished by the busying elevator, without any reply from base elevator. But, the upward call signal from below the busying elevator will be replied by base elevator.

When the busing elevator lifts down, the any direction calls from above the elevator and the upward call from below the elevator will be replied by the base elevator to start to take the passengers, without any reply from busing elevator. But, the downward call signal from below the busing elevator will be finished by busing elevator.

When the busing elevator running and the base elevator has no condition to start, the lots of floor call still exist after an extended period of time and will be replied by base elevator. 
The electrical apparatus control system module mainly realizes the recognition of schematic circuit diagram and major electrical parts. The electrical control system module mainly controls the start of tractor motor and portal crane, moving direction, slowdown and stop, and manages the order signals of layer display, floor calls, car order and safety protection. The recognition of major electrical parts contains control box, light box of layer, switch device, which including image sketch and text interpretation.

The electric drive system module realizes electrical control simulation and provides the analysis for electrical drive, respectively including the starting, stable operation and braking deceleration processes during the ascent and descent. The elevator drive system presently can be divided into the DC motor, AC motor, permanent magnet motor.

The car system module simulates and analysis the car structure, and provides the structure diagram.

The door system realizes the simulation of car door, hall switch and principle analysis function.

The traction system realizes the working condition simulates of traction drive and status display of elevator parts under different working conditions, which contains motor, reducer, brake. And also the system can provide the information display for wire rope structure of tractor, performance requirement, rope way, etc.

The guidance system module can analysis the structure of guide rail, track frame, guide shoe.

The safety protection system module can realizes the function analysis on mechanical and electrical safety protection.

The weight balance system module can analysis the weight and weight compensation device structure.

\section{Conclusion}

The virtual elevator assistant training system, as the training software for safety administrator and maintenance operators of elevator, has characters of low cost, convenient, flexible, safety, energy saving and without limits of time and site. The safety administrator and maintenance operators of elevator could be acquainted with the operation law and operation management function by operating the virtual elevator, which provides a new development direction for the training of Elevator operators.

\section{References}

[1] Conference proceedings of virtual inst.in Education, MIT June 12, (1997)163-182.

[2] ZHU Xiaodong, ZENG Qingshan, FENG Dongqing, The design of PLC communication in virtual elevator system, CONTROL \& AUTOMATION, 22(2006) 29-31.

[3] TIAN Min, Elevator remote monitoring system based on RS-485 and Kingview software, Master, Sichuan University, China, 2005.

[4] DENG Xuexiong, ZHANG Yueling, ZHOU Yun, et al. Research on elevator simulation based on VRML, J. Eng. Grap. 2(2009)91-95.

[5] LIU Wei, Design of virtual elevator based on SIMENS S7-300PLC, Master, Ocean University of China, China, 2009.

[6] ZONG Qun, LUO Xinyu, WANG Zhonghai, Development and application of virtual elevator system, Manuf. Autom. 24(2002)56-58.

[7] National Instruments corporations LabVIEW user manual, NI, 2003. 